\title{
ДЕФИНИЦИЯ «УСЛОВИЯ СОЦИАЛЬНОГО НАЙМА» В ЖИЛИЩНОМ ПРАВЕ: СУЩНОСТЬ, СОДЕРЖАНИЕ, ПРОТИВОРЕЧИЯ
}

\begin{abstract}
Аннотация: Предметом исследования в данной статье является сущность и содержание дефиниции «условия социального найма» как одной из фундаментальных категорий жилищного права. Автором показано, что, несмотря на наличие данной категории в жилищном праве, ее сущчность и содержание в законодательстве не раскрытыл. Данное обстоятельство приводит к ограничению прав граждан на приватизацию занимаемых жильх помещений. Предлагается внести указанные элементы в качестве содержания дефиниции «условия социального найма» в Закон Российской Федераџии от 04.07.1991 № 1541-I «О приватизаџии жилищного фонда в Российской Федерации». В иелом, законодательное закрепление содержания указанной дефиниции позволит упорядочить правоотношения в сфере приватизации жильх помещений. Методы исследования - анализ, синтез, обобщение, сравнение, группировка. В основу исследования положен метод сравнения. Автор анализирует сходную категорию - условия договора социильного найма - сущзность и содержание которой определены Жилищнылм кодексом Российской Федерации. Вместе с тем автор приводит аргументы не тождественности этих понятий. Рассматривая судебную практику, автор выделяет элементы условий соииального найма, принимаемых судами для признания жилищных прав граждан. Объединены и сгруппированы элементы условий договора социильного найма и элементы, принимаемые судами для условий сочиального найма. Новизна исследования заключается в формировании собственного набора элементов, характерных для условий социального найма. Предложенньий автором вариант отражает существо процессов в современной правоприменительной практике, и способен устранить проблему отсутствия законодательно установленной дефиниции условия социильного найма.
\end{abstract}

Ключевые слова: Условия сочиального найма, договор сочиального найма, жилище, жилищное право, приватизация, судебная практика, жилищные права граждан, условия договора, ограничение прав, Жилищный кодекс.

Abstract: The subject of this research is the essence and content of the definition "terms of social housing" as one of the fundamental categories of property law. The author demonstrates that despite the presence of this category in property law, its nature and content are not clarified in the legislation. This circumstance leads to limitation of citizens' rights to privatize the residence they occupy. A proposal is made to implement these elements as the content of the definition of the "terms of social housing" into the law of the Russian Federation from 07.04.1991 No. 1541-I "About privatization of housing stock in the Russian Federation". Overall, the legislative recognition of the content of this definition will allow organizing the legal relations in the area of privatization of housing. Reviewing the legal precedent, the author highlights the elements of the terms of social housing ruled by the courts in recognition of the housing rights of citizens. The novelty of this research consists in formation of original set of elements characteristic for the terms of social housing. The version proposed by the author reflects the substance of the processes in the modern judicial practice and is capable of resolving the issue of lack of legally defined terms for social housing in Russia.

Keywords: Terms of social housing, Social housing agreement, Residence, Property law, Privatization, Legal precedent, Housing rights, Terms of agreement, Limitation of rights, Housing Code.

июле 1991 года вступил в силу Закон Российской Федерации от 04.07.1991 № 1541-I «О приватизации жилищного фонда в Российской Федерации» [1]. За время, прошедшее с момента вступления его в силу, многие сотни тысяч граждан нашей страны приватизировали занимаемые ими жилые помещения, реализовав своё право на жилище, установленное ст. 40 Конституции Российской Федерации. Как указано в преамбуле Постановления Пленума Верховного Суда РФ от
02.07.2009 № 14, «конституционное право граждан на жилище относится к основным правам человека и заключается в обеспечении государством стабильного, постоянного пользования жилым помещением лицами, занимающими его на законных основаниях». Безусловно, приватизация жилых помещений позволяет закрепить возможности стабильного, постоянного пользования жилым помещением.

Согласно ст. 2 указанного Закона, граждане Российской Федерации, имеющие право пользова- 


\section{Право и политика 11 (191) • 2015}

ния жилыми помещениями государственного или муниципального жилищного фонда на условиях социального найма, вправе приобрести их на условиях, предусмотренных настоящим Законом, иными нормативными правовыми актами Российской Федерации и нормативными правовыми актами субъектов Российской Федерации, в общую собственность либо в собственность одного лица, в том числе несовершеннолетнего, с согласия всех имеющих право на приватизацию данных жилых помещений совершеннолетних лиц и несовершеннолетних в возрасте от 14 до 18 лет [1].

Как видно из вышеприведенного текста, право пользования жилым помещением на условиях социального найма является основополагающим условием для приобретения в собственность жилого помещения. Однако, далее ни в одном нормативноправовом акте ни понятие «условия социального найма», ни его элементы не раскрываются. Равно как и не раскрывается это понятие в самом Законе Российской Федерации от 04.07.1991 № 1541-I «O приватизации жилищного фонда в Российской Федерации». Таким образом, отсутствие четкого определения, что же составляет «условия социального найма», априори создаёт препятствия для реализации гражданами конституционного права на жилище.

На практике необходимым критерием выполнения «условий социального найма» для приватизации являлись договоры социального найма. Скорее всего, наличие договора социального найма может свидетельствовать о выполнении «условий социального найма». Но ведь условия договора социального найма могут быть выполнены и без фиксации в договоре. Этой проблеме и будет посвящено наше исследование.

Впервые в законодательстве Российской Федерации понятие договора социального найма было закреплено в ст. 1 Закона Российской Федерации от 24.12.1992 № 4218-1 «Об основах федеральной жилищной политики»: договор социального найма жилого помещения - соглашение, по которому собственник государственного или муниципального жилищного фонда либо управомоченное им лицо (наймодатель) предоставляет во владение и пользование гражданину (нанимателю) благоустроенное жилое помещение, как правило, в виде квартиры в пределах нормы площади жилого помещения, а наниматель обязуется использовать его для проживания и своевременно вносить плату за жилое помещение [2].

В Жилищном кодексе Российской Федерации (далее - ЖК РФ) понятие договора социального найма отсутствует, однако некоторые статьи ЖК РФ содержат его основные черты:

1. предмет договора - по договору социального найма жилого помещения одна сторона - собственник жилого помещения государственного жилищного фонда или муниципального жилищного фонда (действующие от его имени уполномоченный государственный орган или уполномоченный орган местного самоуправления) либо управомоченное им лицо (наймодатель) обязуется передать другой стороне - гражданину (нанимателю) жилое помещение во владение и в пользование для проживания в нем на условиях, установленных настоящим Кодексом (п. 1 ст. 60);

2. условие признания в улучшении жилищных условий (п. 2 и 3 ст. 49);

3. условие нахождения жилого помещения в государственном или муниципальном жилищном фонде (ст. 49, ст. 19);

4. условие предоставления жилого помещения собственником или уполномоченным государственным органом (п. 1. ст. 60);

5. условие того, что жилое помещение является изолированным (ст. 62);

6. предоставление жилого помещения без установления срока проживания (п. 2 ст. 62).

Различие подходов законодателя к проблеме определения содержания понятий «условия социального найма» и «договор социального найма» представлено в таблице 1.

Таблица 1. Различие подходов законодателя к проблеме определения содержания понятий «условия сочиального найма» и «договор соииального найма».

\begin{tabular}{|l|l|l|}
\hline Категория & Условия социального найма & \multicolumn{1}{|c|}{ Договор социального найма } \\
\hline Содержание & Не определено & Договор, в соответствии с которым одна сторона - собствен- \\
& & $\begin{array}{l}\text { ник жилого помещения государственного жилищного фонда } \\
\text { или муниципального жилищного фонда (действующие от его } \\
\text { имени уполномоченный государственный орган или }\end{array}$ \\
\hline
\end{tabular}


DOI: 10.7256/1811-9018.2015.11.16628

При цитировании этой статьи сноска на dоі обязательна

Человек и государство

\begin{tabular}{|l|l|l|}
\hline & & $\begin{array}{l}\text { уполномоченный орган местного самоуправления) либо упра- } \\
\text { вомоченное им лицо (наймодатель) обязуется передать другой } \\
\text { стороне - гражданину (нанимателю) жилое помещение во } \\
\text { владение и в пользование для проживания в нем на условиях, } \\
\text { установленных Жилищным кодексом Российской Федерации }\end{array}$ \\
\hline Условия & Установлены Жилищным кодексом Российской Федерации \\
\hline
\end{tabular}

На первый взгляд может показаться, что никакого противоречия, а, следовательно, никакой проблемы здесь нет. Гражданин для выполнения условий социального найма должен выполнить условия, установленные ЖК РФ для договора социального найма. Однако, не всегда и не во всех случаях заключение такого договора возможно, несмотря на то, что условия, установленные для его заключения, выполнены. Кроме того, как свидетельствует судебная практика, условиями социального найма могут быть признаны и иные обстоятельства. Так, например, при решении вопроса о признании права пользования жилым помещением на условиях социального найма суды выносят положительные решения, принимая во внимание следующее:

1. законность вселения в жилое помещение, постоянное проживание в жилом помещении, фактическое исполнение обязанностей по договору (решение Свердловского районного суда г. Иркутска от 11.06.2011 по делу № 2-1772/11, решение Советского районного суда г. Томска от 23.04.2012 по делу № 2-1080/12, решение Советского районного суда г. Томска от 06.02.2013 по делу № 2-304/13);

2. проживание на законных основаниях, наличие права состоять на учете в качестве нуждающихся в жилых помещениях, наличие дополнительных гарантий, предусмотренных ст. 13 Федерального Закона Российской Федерации от 29.12.2004 № 189-Ф3 «О введении в действие Жилищного кодекса Российской Федерации» (решение Железнодорожного районного суда Орловской области по делу № 2-785/13).

Отметим, что отсутствие законодательно определенного содержания понятия «условия социального найма» позволяют судам смешивать или подменять его договором социального найма. Так, например, Ленинский районный суд г. Владивостока 08.10.2013 вынес решение о признании права пользования жилым помещением на условиях социального найма (дело № 2-5822/2013), а Судебная коллегия Приморского краевого суда своим решением от 18.12.2013 (дело № 33-10611) отменила это решение на основании того, что спорное жилое помещение относится к специализированному жилищному фонду, для которого договоры социального найма не предусмотрены. Хотя в исковых требованиях о договоре речи не было. Таким образом, отсутствие законодательно закрепленного содержания понятия «условия социального найма» позволяет судам не только использовать различные элементы, связанные с договором социального найма, дополняя иными условиями, но и подменять одно понятие другим.

Объединив условия, содержащиеся в ЖК РФ для заключения договора социального найма и условия, дополнительно принимаемые во внимание судами для признания права пользования жилыми помещениями на условиях социального найма, приходим к следующему перечню:

1. признание нуждающимся в предоставлении жилого помещения;

2. жилое помещение относится к государственному или муниципальному жилищному фонду;

3. жилое помещение предоставлено уполномоченным органом;

4. жилое помещение является изолированным;

5. проживание без установления срока;

6. законность вселения в жилое помещение;

7. постоянное проживание в жилом помещении;

8. фактическое исполнение обязанностей по договору (оплата коммунальных услуг, подержание помещения в надлежащем состоянии);

9. проживание на законных основаниях;

10. невозможность выселения без предоставления иного жилого помещения (дополнительные гарантии, предусмотренные ст. 13 Федерального Закона Российской Федерации от 29.12.2004 № 189-Ф3 «О введении в действие Жилищного кодекса Российской Федерации»).

Далее, из этого перечня необходимо исключить те пункты, которые в силу различных причин, по нашему мнению, не могут быть условиями 
DOI: $10.7256 / 1811-9018.2015 .11 .16628$

При цитировании этой статьи сноска на dоі обязательна

\section{Право и политика $11(191) \cdot 2015$}

социального найма (рисунок 1). Здесь необходимо иметь ввиду, что условия ЖК РФ о социальном найме относятся к предоставлению жилых помещений и не касаются жилых помещений, уже когда-либо ранее предоставленным.

Вначале рассмотрим фактор времени. Как уже отмечалось, словосочетание «условия социального найма» в законодательстве Российской Федерации впервые появилось в 1991 г. А условия для заключения договора социального найма содержатся в действующем ЖК РФ, вступившем в силу только в 2005 г. При этом, основным условием заключения такого договора является предоставление жилого помещения. Но ведь жилые помещения предоставлялись гражданам и до 2005 г. Следовательно, в силу положений ч. 1 ст. 6 ЖК РФ гражданам, которым жилые помещения предоставлены до введения в действие ЖК РФ, нет необходимости заново получать, а соответствующим органам, предоставлять уже занятые этими гражданами жилые помещения. Кстати, одним из оснований отмены Судебной коллегией Приморского краевого суда (дело № 33-10611) решения Ленинского районного суда г. Владивостока (дело № 2-5822/2013) явилось «отсутствие принятого с соблюдением требований ЖК РФ решения органа местного самоуправления решения о предоставлении жилого помещения, состоящему на учете в качестве нуждающегося в жилом помещении (части 3 и 4 статьи 57, статья 63 ЖК РФ)». Здесь для Судебной коллегии Приморского краевого суда не сыграло никакой роли то обстоятельство, что жилое помещение было предоставлено в 1993 году, то есть, за 12 лет до вступления в действие норм ЖК РФ. Равно как и то обстоятельство, что согласно ч. 1 ст. 6 ЖК РФ акты жилищного законодательства применяются к жилищным отношениям, возникшим после введения его (ЖК РФ) в действие. То есть, подменив понятие «условия социального найма» на «договор социального найма», суд нашел условие, которое было не выполнено для договора социального найма и отказал в праве проживания на условиях социального найма.

Таким образом, пункт о признании нуждающимся в предоставлении жилого помещения необходимо исключить. Более того, в силу определенных причин не все граждане, жилые помещения которым были предоставлены до 2005 г., могут быть признаны нуждающимися в улучшении жилищных условий по критериям ЖК РФ.
Отнесение жилого помещения к государственному или муниципальному жилищному фонду является безусловным для приватизации жилого помещения, равно как и его предоставление уполномоченным органом.

Положение о законности вселения в жилое помещение, по нашему мнению, можно оставить. Особенность в том, что жилые помещения различных видов жилищного фонда в России предоставлялись по-разному. Например, для поселения в общежитие в 90-х годах прошлого века требовалось не только решение администрации, но и решение профсоюзного комитета. В настоящее время в жилых помещениях специализированного жилищного фонда проживают тысячи людей, которые не имеют на руках вообще никаких документов (общежития учебных заведений, бывших госучреждений, совхозов и т.д.). Но несоблюдение порядка вселения не означает, что эти люди проживают незаконно. В судебном порядке их вселение и проживание в большинстве случаев признается законным.

Пункт о постоянном проживании в жилом помещении необходимо оставить, так как постоянное, стабильное пользование жилым помещением является с одной стороны - реализацией права на жилище, и подтверждением воли и намерений проживающих - с другой. Оплата коммунальных платежей и содержание жилого помещения в надлежащем состоянии является обязанностью любого гражданина независимо от формы собственности, вида жилищного фонда, срока проживания и иных обстоятельств.

Положение о невозможности выселения без предоставления иного жилого помещения корреспондирует условию проживания без установления срока, установленного п. 2. ст. 60 ЖК РФ. Его необходимо оставить в силу следующих причин. Во-первых, невозможность выселения свидетельствует о бессрочном характере проживания. Это обстоятельство соответствует выполнению требований п. 2 ст. 60 ЖК о том, что договор социального найма заключается без установления срока его действия, то есть, без установления срока проживания. Во-вторых, выселение с предоставлением другого жилого помещения возможно только в случае предоставления жилого помещения опять же на неограниченный срок, то есть, без установления сроков проживания. В-третьих, бессрочность проживания является государственной гарантией обеспечения жилищных прав граждан. 
DOI: $10.7256 / 1811-9018.2015 .11 .16628$

При цитировании этой статьи сноска на dоі обязательна

Человек и государство

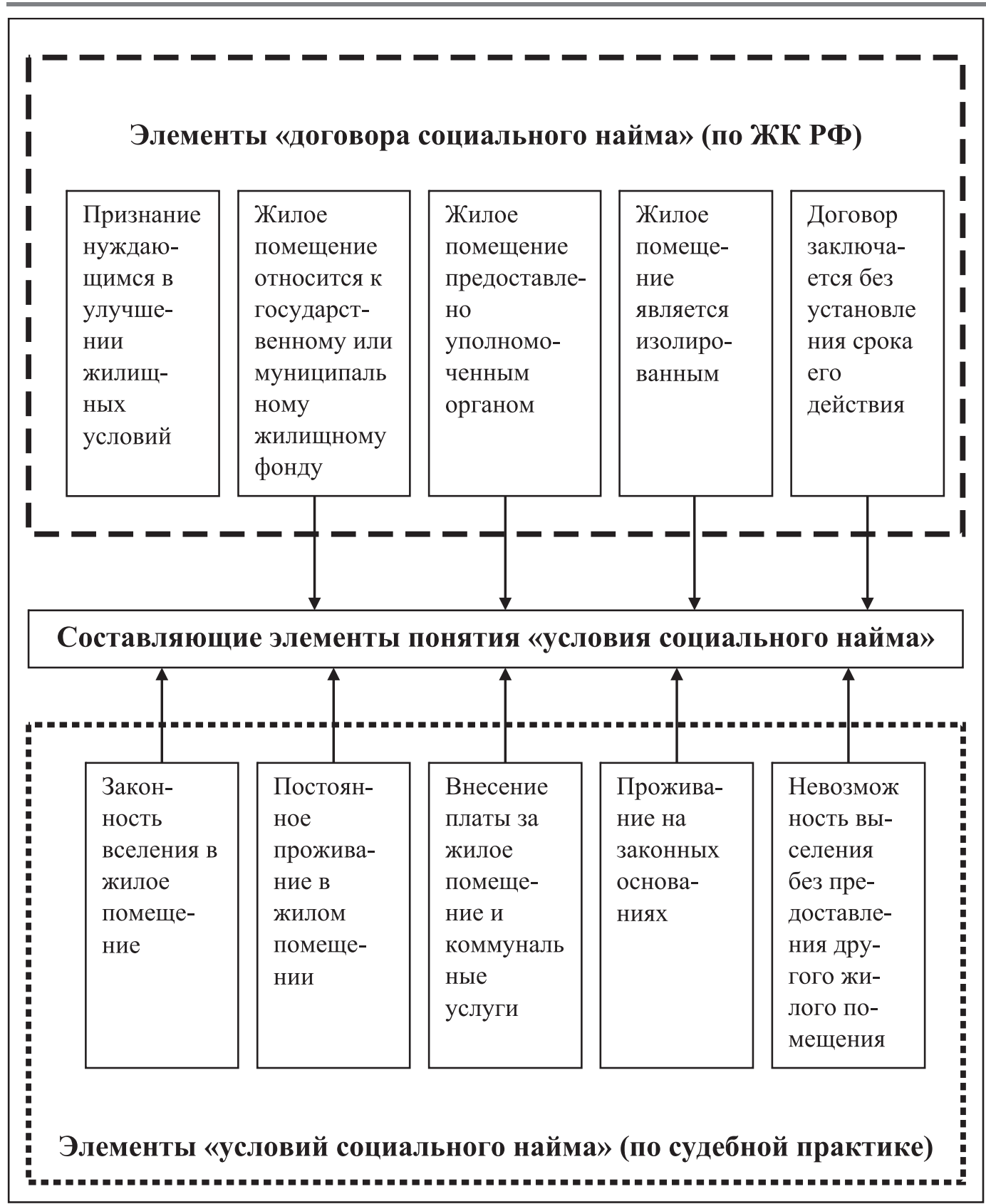

Рис 1. Элементы, определяющие содержсание дефиниции «условия социального найма» (исходя из условий договора социального найма и судебной практики).

Таким образом в понятие «условия социального найма» необходимо включить одновременное выполнение следующих условий:

- граждане проживают в жилом помещении, относящемся к государственному или муниципальному жилищному фонду; жилое помещение предоставлено уполномоченным органом и на законных основаниях, жилое помещение является изолированным, жилое помещение используется для проживания на законных основаниях без установления срока проживания, граждане вносят плату за проживание и коммунальные услуги, граждане не могут быть выселены без предоставления другого жилого помещения.

Учитывая вышеизложенное, предлагаем внести указанные элементы в качестве содержания дефиниции «условия социального найма» в Закон Российской Федерации от 04.07.1991 № 1541-I «О приватизации жилищного фонда в Российской Федерации». В целом, законодательное закрепление содержания указанной дефиниции позволит упорядочить правоотношения в сфере приватизации жилых помещений. 
DOI: 10.7256/1811-9018.2015.11.16628

При цитировании этой статьи сноска на доі обязательна

\section{Право и политика 11 (191) 2015}

\section{Библиография:}

1. Информационно-правовой портал Гарант. Режим доступа: http://base.garant.ru/10105719/. Дата обращения: 10.09.2015.

2. Информационно-правовой портал Гарант. Режим доступа: http://base.garant.ru/10136646/. Дата обращения: 10.09.2015.

3. Критская С.Б. Жилищно-коммунальное хозяйство и городские жители: диалог или борьба? // Урбанистика. - 2014. - 4. - C. 31 - 38. DOI: 10.7256/2310-8673.2014.4.14585. URL: http://www.e-notabene.ru/urb/article_14585.html

4. Стукалов А.В. Правовые аспекты полномочий органов местного самоуправления в сфере жилищно-коммунального хозяйства и особенности их реализации // NB: Административное право и практика администрирования. - $2012 .-1$. - C. 24 - 83. URL: http://www.e-notabene.ru/al/article_479.html

5. Стукалов А.В. Компетенция органов местного самоуправления в области жилищно-коммунального хозяйства. // Административное и муниципальное право. - 2010. - 12. - С. $30-35$.

6. Г. А. Колобова Российская приватизация как политико- государственный механизм преобразования отношений собственности // Политика и Общество. - 2012. - 3. - С. 13 - 22.

7. Винницкий А.В. Публично-правовые основы государственной и муниципальной имущественной поддержки. // Административное и муниципальное право. - 2011. - 3. - С. 13 - 20.

8. Чернышев А.И. Актуальные вопросы управления имуществом муниципального образования // Административное и муниципальное право. - 2014. - 10. - C. 1025 - 1030. DOI: 10.7256/1999-2807.2014.10.12097.

\section{References (transliterated):}

1. Kritskaya S.B. Zhilishchno-kommunal'noe khozyaistvo i gorodskie zhiteli: dialog ili bor'ba? // Urbanistika. - 2014. - 4. - C. 31 - 38. DOI: 10.7256/2310-8673.2014.4.14585. URL: http://www.e-notabene.ru/urb/article_14585.html

2. Stukalov A.V. Pravovye aspekty polnomochii organov mestnogo samoupravleniya v sfere zhilishchno-kommunal'nogo khozyaistva i osobennosti ikh realizatsii // NB: Administrativnoe pravo i praktika administrirovaniya. - 2012. - 1. - C. 24 - 83. URL: http:// www.e-notabene.ru/al/article_479.html

3. Stukalov A.V. Kompetentsiya organov mestnogo samoupravleniya v oblasti zhilishchno-kommunal'nogo khozyaistva. // Administrativnoe i munitsipal'noe pravo. - 2010. - 12. - C. $30-35$.

4. G. A. Kolobova Rossiiskaya privatizatsiya kak politiko-gosudarstvennyi mekhanizm preobrazovaniya otnoshenii sobstvennosti // Politika i Obshchestvo. - 2012. - 3. - C. $13-22$.

5. Vinnitskii A.V. Publichno-pravovye osnovy gosudarstvennoi i munitsipal'noi imushchestvennoi podderzhki. // Administrativnoe i munitsipal'noe pravo. - 2011. - 3. - C. $13-20$.

6. Chernyshev A.I. Aktual'nye voprosy upravleniya imushchestvom munitsipal'nogo obrazovaniya // Administrativnoe i munitsipal'noe pravo. - 2014. - 10. - C. 1025 - 1030. DOI: 10.7256/1999-2807.2014.10.12097. 